\title{
Investigating the Impact of Big Data Analytics on Perceived Sales Performance: The Mediating Role of Customer Relationship Management Capabilities
}

\author{
Muhammad Shahbaz $\left(\mathbb{D},{ }^{1,2}\right.$ Changyuan Gao $\mathbb{D}^{1},{ }^{1}$ Lili Zhai, ${ }^{1}$ Fakhar Shahzad $\left(\mathbb{D},{ }^{3}\right.$ \\ Adnan Abbas, ${ }^{1}$ and Rimsha Zahid $\mathbb{D}^{1}$ \\ ${ }^{1}$ School of Economics and Management, Harbin University of Science and Technology, Harbin 150080, China \\ ${ }^{2}$ Lyallpur Business School, Government College University, Faisalabad 38000, Pakistan \\ ${ }^{3}$ School of Management, Jiangsu University, Zhenjiang, China
}

Correspondence should be addressed to Muhammad Shahbaz; shahbaz755@yahoo.com and Changyuan Gao; gaocy2002@126.com

Received 15 April 2020; Accepted 1 June 2020; Published 22 June 2020

Academic Editor: Michele Scarpiniti

Copyright $\odot 2020$ Muhammad Shahbaz et al. This is an open access article distributed under the Creative Commons Attribution License, which permits unrestricted use, distribution, and reproduction in any medium, provided the original work is properly cited.

\begin{abstract}
A persistent question for information technology researchers and practitioners is how big data analytics (BDA) can improve sales performance. Therefore, this study proposed a research model to investigate the impact of BDA on perceived sales performance in accordance with the resource-based view (RBV) and dynamic capability theory. The 416 valid responses collected from the employees of pharmaceutical organizations were analyzed using structural equation modelling to test the proposed research model. Results indicated that the BDA and customer relationship management (CRM) capabilities shared a strong positive impact on perceived sales performance. BDA, as organizational resources, creates organizational dynamic capabilities, such as CRM capabilities. BDA and CRM capabilities can influence perceived sales performance. Furthermore, CRM capabilities have a significant mediating impact on the relationships between BDA and perceived sales performance. This study also highlighted the practical and theoretical implications of the proposed model, the research limitations, and the future research directions.
\end{abstract}

\section{Introduction}

Big data analytics (BDA) has received special attention due to its dynamic decision-making capabilities [1]. Today's technology-oriented world brings numerous unprecedented opportunities and novel complexities that contribute to improving decision-making capabilities and obtaining competitive advantages $[2,3]$. BDA refers to the complex process of obtaining information like the hidden patterns, unidentified correlations, users' preferences, and market trends from the massive amount of structured and unstructured data that assist organizations for efficient decision-making [4]. In simple words, BDA is defined as "the strategy of analyzing large volumes of data, or big data," which is collected through a variety of sources, such as images, sensors, videos, social media contents, sales transaction entries, and many others. Researchers and practitioners have related $\mathrm{BDA}$ with the subsequent frontier for competition, innovation, and productivity [5], whereas others have claimed that $\mathrm{BDA}$ is a revolution that will change the way we work, think, and live [6]. However, the research on the potential of BDA is still at the fundamental stage and generally fails to consider the mechanisms through which the investments in $\mathrm{BDA}$ are converted into competitive performance $[7,8]$. The literature provides vital knowledge on the challenges, benefits, and outcomes of BDA, but little is known about how the practice of BDA in organizations creates value for organizations, becomes the competitive edge of organizations, and enhances organizational or sales performance $[9,10]$. The proponents of $\mathrm{BDA}$ application in the USA claim that the proper application of BDA in healthcare organizations, including pharmaceutical 
organizations, reduces costs by $\$ 300$ million per annum, improves decision-making capabilities, reduces managerial complexities, and improves organization-customer interactions [5].

As for pharmaceutical organizations, they face the perennial challenge of ensuring organizational sales performance $[11,12]$. Most pharmaceutical organizations use different sales force automation (SFA) systems to manage sales-related activities [13]. SFA systems are supposed to make analyzed information about sales forecasting, inventory control, and customer needs available, and the customer wants to help build profitable relationships with customers, maximize pipeline opportunities, and establish good sales communication history to achieve efficiency in decisionmaking $[14,15]$. Organizations around the world invest millions of dollars annually on SFA systems to achieve decision-making efficacy and thereby boost sales performance and to build and maintain profitable relations with customers; unfortunately, sales forces have generally been dissatisfied with SFA systems $[15,16]$. The literature reports that $61 \%$ of SFA systems fail to fulfill the needs of sales forces in terms of analyzed information for enhancing sales performance [17-19]. Several causes of SFA failure have been highlighted. One is the lack of storage and analysis capabilities of SFA [18-20]. Another is insufficient input data from organizations, with the primary source of input data in the SFA system being boundary spanners $[17,20]$. In the present era of big data, input data from all available sources, such as social media (e.g., social, electronic, and mobile commerce websites), sales forums, competitor data, and other stakeholder data, are mandatory for ensuring the efficient output of analyzed information [21-24]. In the management of organizational sales performance, BDA can store and analyze big data of massive amounts, variety, and velocity from all possible resources, including social commerce sites, electronic commerce sites, mobile commerce sites, competitors, substitute products or service organizations, and decision-making [25-28]. Therefore, BDA may solve the existing sales force problems, especially in pharmaceutical organizations. However, studies on this particular concern are limited. Therefore, to fulfill this research gap, the current study aims to investigate the impact of BDA on perceived sales performance (PSP), especially in pharmaceutical organizations.

Customer relationship management (CRM) is the primary and most crucial responsibility of any marketing department, and it is aimed at creating and maintaining strong customer relationships to improve sales performance [29]. The literature on sales performance considers CRM capabilities as mandatory for better sales performance, and many prior studies concluded the essential role of CRM capabilities in sales performance [30-34] but less focusing on this important variable in the context of BDA. One of the functions of SFA systems is to provide information related to customers to increase CRM capabilities that ultimately improve organizational sales performance [35]. BDA is also the latest form of information technology (IT), and prior studies conceptually concluded that BDA outcomes can influence organizational performance $[28,36]$ and CRM capabilities [37, 38]. Furthermore, CRM capabilities are considered as dynamic capabilities that can increase PSP. Previous studies mostly emphasized the impact of BDA capabilities on organizational performance or sales performance [39-41] and ignored the impact of CRM capabilities, which is the primary predictor of the sales performance. The lack of previous scholars' intention to examine employee's perception about the impact of BDA on sales performance through CRM capabilities motivates the authors to perform an in-depth investigation. To bridge this gap, the current study considers that BDA has an impact on CRM capabilities and CRM capabilities will enhance the PSP, especially in pharmaceutical organizations. This study has investigated the following key research question: What is the impact of BDA on PSP through CRM capabilities in pharmaceutical organizations?

This study aims to investigate the impact of BDA on PSP based on users' perception and propose a comprehensive research model. This study considers the resource-based view (RBV) and dynamic capabilities theory as the theoretical lens for constructing the proposed research model. The RBV describes organizations as possessing resources that help achieve a competitive edge [42], and dynamic capabilities theory determines how resources are developed and how IT resources can build or create dynamic capabilities in organizations to improve organizational performance $[43,44]$. Therefore, under the theoretical lens, this study proposes a number of prominent BDA benefits (that organizations automatically generate after practicing BDA) as measuring variables of $\mathrm{BDA}$ and considers these BDA benefits as resources for organizations in creating dynamic capabilities, such as CRM capabilities. This study also considers the most used and influential CRM capabilities, such as customer interaction management capabilities (CIMCs), customer relationship upgrading capabilities (CRUCs), and customer win-back capabilities (CWBCs), as used by many prior studies [31, 32, 45, 46]. These BDA benefits (better customer service [BCS], personalization, advanced analytics $[\mathrm{AA}]$, and improved relational knowledge [IRK]), along with CRM capabilities, influence the PSP of pharmaceutical organizations. The novel concept of the mediating role of CRM capabilities in the relationship of $\mathrm{BDA}$ and PSP is proposed in the present study's context.

Additionally, the paper is further divided into the following sections: Section 2 presented the theoretical framework and hypotheses. Section 3 of the paper contained the material and methods used. Results and discussion are elaborated in Section 4 and Section 5. Section 6 provided the conclusion of the study and Section 7 contained practical and theoretical implications, limitations, and future work.

\section{Theoretical Framework and Hypothesis}

The RBV and dynamic capabilities theories were adopted as the theoretical foundation for developing the research model. The RBV emerged from strategic management to demonstrate how different organizational resources contribute to organizational performance [47]. RBV has been considered as a principle theory in the last two decades for 
exploring different IT outcomes as resources that influence firm performance, and many studies concluded that different IT outcomes could add value to firm performance $[7,48,49]$. However, many prior studies criticized RBV for its lack of explanatory power with regard to how different IT resource outputs can create different capabilities in organizations $[40,50,51]$. Similarly, dynamic capabilities theory was proposed by Teece and Pisano in 1994 [52] to overcome the limitations and shortcomings of the RBV. The RBV ignores the surroundings of organizational resources and the development of resources, such as how these resources can be integrated with others and how such integration can develop new capabilities [40, 42, 53-55]. The RBV focuses on selecting existing factors and uses them to obtain a competitive edge and increase organizational performance, whereas dynamic capabilities theory focuses on developing capabilities through existing resources and factors that can react according to the dynamic environment [1]. The RBV places emphasis on the sustainability of organizational performance through existing resources, whereas the concept of dynamic capabilities indicates that sustainability in this era of changing environment cannot be achieved through the outcomes of static resources and that resources should be developed to enhance capabilities for tackling environmental changes [39]. The study of Wade and Hulland concluded that information system or technology outcomes as resources could create dynamic capabilities in organizations and that the enhancement of performance is solely dependent on the outcomes provided by IT [44].

Given that the study aims to investigate employees' perception about the impact of BDA on sales performance through the organization dynamic capabilities, the choice of dynamic capabilities theory as partially supported by RBV to develop a comprehensive research framework is deemed suitable. The existing view of big data has been extended by the notion of $\mathrm{BDA}$ that is important to transform the data into valuable insights, and its implication in the decisionmaking process to improve the sales performance. Therefore, it is worthwhile to examine the impact of $\mathrm{BDA}$ on various organization dynamic capabilities and how they affect sales performance. On the basis of the RBV and dynamic capabilities theory, the current work considers BDA measures through its most influential benefits as IT resource of organizations [56] and CRM capabilities as dynamic capabilities. Moreover, BDA benefits as resources of organizations are expected to develop the CRM capabilities of pharmaceutical organizations in Pakistan and enhance their PSP. CRM capabilities are also proposed to enhance the PSP of pharmaceutical organizations and mediate of the relationship between BDA on PSP. Figure 1 presents the proposed research model.

2.1. Benefits of Big Data Analytics. The literature on BDA uses its benefits to directly and indirectly measure the overall relationship between BDA and organizational performance through different capabilities $[37,38]$ and also investigate the impact of BDA on the service innovation [57]. In this study, the most prominent perceived benefits of BDA are

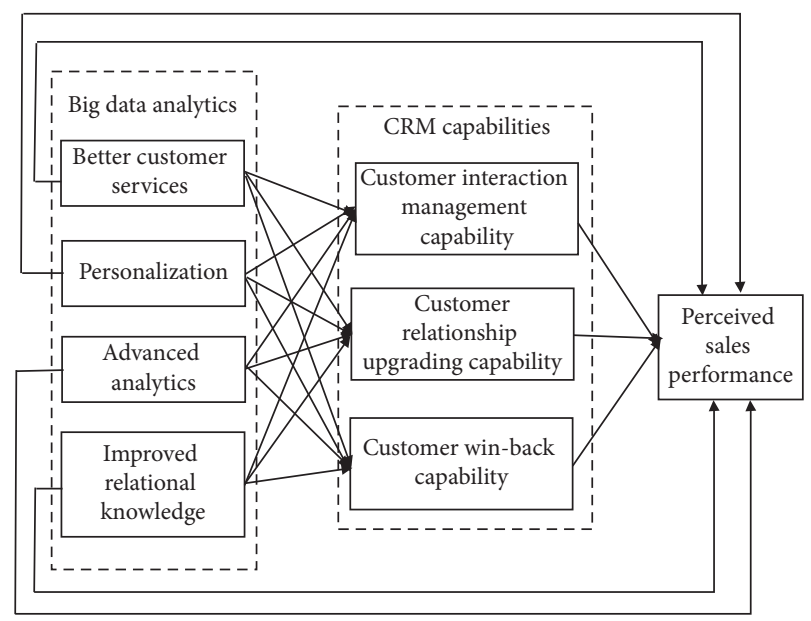

Figure 1: Research model.

incorporated on the basis of a systematic literature analysis (Table 1). The BDA benefits are considered as the IT resources of organizations. As a well-established myth, the adoption and implementation of any technology will provide several benefits to organizations, and these benefits will ultimately become the resources of organizations for competitive advantage $[69,70]$. Therefore, this study considers BDA benefits, such as BCS, personalization, AA, and the IRK, as resources of organizations for developing CRM capabilities and increasing PSP.

2.1.1. Better Customer Service. BCS is the first step in improving the CRM capabilities of organizations [71]. Prior studies already established the relationship of BCS with PSP and CRM capabilities [10, 72]. In the study of BDA, Lee highlighted the importance of BCS as benefits of BDA [59]. The study explained that BCS is possible due to the data gathering method of $\mathrm{BDA}$ as such data originates from all possible resources of the target segment of customers. Furthermore, the study claimed that BDA also supports the prediction of customer problems, such as real-time demands and fraudulent activities. Akter and Fosso demonstrated $\mathrm{BDA}$ in the context of e-commerce and concluded that BDA could provide more BCS than other existing systems and thus greatly influences the sales performance of organizations [56]. Many studies already concluded the positive relationship of BCS as IT resource of the organization with CIMC, CRUC, and CWBC in different contexts other than BDA such as marketing effectiveness [32], the performance of services industry [45], and overall organizational performance [31].

The studies mentioned above already empirically established the significant relationship of BCS with PSP and CRM capabilities (CIMC, CRUC, and CWBC) in contexts other than $\mathrm{BDA}$, but few studies highlighted the importance of this factor in the context of BDA. The literature on the potential relationship of this BDA with PSP and CRM capabilities is insufficient. Therefore, the current work incorporates BCS as BDA benefits that will influence PSP and CRM capabilities, such as CIMC, CRUC, and CWBC. 
TABLE 1: Enabling big data analytics benefits.

\begin{tabular}{|c|c|c|}
\hline BDA benefits & Description & Related studies \\
\hline $\begin{array}{l}\text { Better customer } \\
\text { services }\end{array}$ & $\begin{array}{l}\text { The degree to which the employees perceive the information } \\
\text { as an output provided by BDA would help provide better } \\
\text { services to customers }\end{array}$ & $\begin{array}{c}\text { Philip Chen and Zhang [58], Akter and Wamba [56], } \\
\text { Lee [59], Doll and Torkzadeh [60], Trivellas and } \\
\text { Santouridis [61] }\end{array}$ \\
\hline Personalization & $\begin{array}{l}\text { The degree to which the pharmaceutical organization } \\
\text { employees perceive that BDA will provide customized } \\
\text { information as an output regarding the customers }\end{array}$ & $\begin{array}{c}\text { Akter and Wamba [56], Lee [59], Parasuraman et al. } \\
\text { [62], Xu et al. [63], Shahzad et al. [64] }\end{array}$ \\
\hline Advanced analytics & $\begin{array}{l}\text { The extent to which the employees of the organizations } \\
\text { perceive that BDA will provide the information regarding } \\
\text { patients by using advanced and latest tools of analyzing data }\end{array}$ & $\begin{array}{c}\text { Akter and Wamba [56], Ji-fan Ren et al. [65], } \\
\text { Raguseo and Vitari [66] }\end{array}$ \\
\hline $\begin{array}{l}\text { Improved relational } \\
\text { knowledge }\end{array}$ & $\begin{array}{l}\text { The degree to which the organization's employees perceive } \\
\text { that outcomes provided by BDA will improve their } \\
\text { knowledge regarding the improvement of relations with the } \\
\text { customers }\end{array}$ & $\begin{array}{l}\text { Akter and Wamba [56], Akter et al. [48], Acharya } \\
\text { et al. [28], Jiang et al. [67], Kim et al. [68] }\end{array}$ \\
\hline
\end{tabular}

H1: BCS has a positive impact on PSP.

H1a: BCS has a positive impact on customer interaction management capability.

H1b: BCS has a positive impact on customer relationship upgrading capability.

H1c: BCS has a positive impact on customer win-back capability.

2.1.2. Personalization. Today's business world is full of competition, and survival is only possible by providing customized products or services [56]. In contexts other than $\mathrm{BDA}$, studies incorporated personalization as a predictor variable to investigate its relationship with PSP and CRM capabilities. For example, Parasuraman et al. considered personalization and reported its impact on PSP in the context of an electronic service quality system [62]. Simanjuntak et al. also highlighted the importance of personalization as an IT system benefits and concluded its positive influence on CRM capabilities [32]. Previous studies in different sectors such as marketing, insurance, banking, and e-commerce already proved the strong relationship of personalization with CIMC, CRUC, and CWBC $[45,73]$ but lacking in the context of BDA.

In the context of BDA, few empirical studies investigated the impact of personalization on PSP and discussed importance of the personalized information provided by BDA and its potential in increasing the PSP and CRM capabilities $[56,59]$. A recent study explored the important of BDA in services personalization in multisector organizations such as insurance, banking, telecommunication, and e-commerce and suggested the need of more empirical studies on it especially in healthcare sector [74]. These studies also suggested that personalization should be empirically investigated in the context of BDA. Therefore, the present study proposes personalization as a BDA benefit that will influence PSP and CRM capabilities (CIMC, CRUC, and CWBC).

H2: Personalization has a positive impact on PSP.

H2a: Personalization has a positive impact on customer interaction management capability.
H2b: Personalization has a positive impact on customer relationship upgrading capability.

$\mathrm{H} 2 \mathrm{c}$ : Personalization has a positive impact on customer win-back capability.

2.1.3. Advanced Analytics. AA is one of the primary benefits of BDA that makes BDA superior to other existing decision support systems [75]. In this study, AA is considered as the advanced analyzed information that a sales person can get by using BDA for better sales performance. As a well-established myth, the results regarding organization sales and CRM improve with the quality of AA [10]. Prior studies in contexts other than BDA justified that AA has a positive influence on PSP and CRM capabilities. For example, Acharya et al. considered AA in investigating sales performance in the context of the fashion industry and concluded that the sales performance of organizations increases with AA quality [28]. Another study incorporated AA as a predictor variable and established its positive impact on CRM capabilities [76]. Prior studies highlighted the importance and empirically proved the positive relationship of AA with CIMC, CRUC, and CWBC [31, 45, 46] but unfortunately this important relationship was ignored in the context of BDA.

In the context of $\mathrm{BDA}$, a recent study explored that different BDA benefits especially the advanced analytical ability of BDA create different dynamic capabilities in the organization that ultimately help improve performance [77]. Investigations into the influence of AA on PSP and CRM capabilities in the context of $\mathrm{BDA}$ are rarely reported. Arunachalam et al. highlighted the importance of AA in the context of supply chain management and concluded that the AA outcome of BDA could influence the PSP of organizations [75]. Therefore, to bridge this gap, the current research proposes that AA as a benefit of BDA has an impact on PSP and CRM capabilities (CIMC, CRUC, and CWBC).

H3: AA has a positive impact on PSP.

H3a: AA has a positive impact on customer interaction management capability.

H3b: AA has a positive impact on customer relationship upgrading capability. 
H3c: AA has a positive impact on customer win-back capability.

2.1.4. Improved Relational Knowledge. Prior studies on different technology benefits already concluded that an organization's relationship with existing and potential customers strengthens as the relational knowledge of employees improves [45]. In the context of decision-making for household purchases, a prior study concluded that IRK can influence the sales performance of the organization [78]. Wang and Feng also proved the positive relationship between IRK and CRM capabilities [45].

As BDA is a concern, existing studies only investigated the importance of IRK in improving organizational performance and CRM capabilities and thus lack empirical investigations. Akter et al. only conceptually highlighted the importance of IRK in improving organizational performance [48]. Another study considered IRK in the context of education and discussed its importance in improving sales and CRM capabilities [31]. Previous studies also reported the positive impact of IRK on CIMC, CRUC, and CWBC in different contexts other than BDA $[31,73,76]$. In the context of BDA, these important relationships of IRK with PSP, CIMC, CRUC, and CWBC are lacking and need to be studied. On the basis of the aforementioned literature, this study proposes that IRK as a benefit of BDA influences PSP and CRM capabilities (CIMC, CRUC, and CWBC).

H4: IRK has a positive impact on PSP.

H4a: IRK has a positive impact on customer interaction management capability.

H4b: IRK has a positive impact on customer relationship upgrading capability.

H4c: IRK has a positive impact on customer win-back capability.

2.2. CRM Capabilities. On the basis of dynamic capabilities theory, this research considers CRM capabilities as dynamic capabilities. CRM capabilities refer to the multifunctional process of building, maintaining, and enhancing relationships with customers in the long term to increase the sales performance of an organization [72]. Thus, to create CRM capabilities, an organization must have a data analytics system or technology, and the quality of CRM capabilities in the organization increases with that of the analyzed information. Furthermore, prior studies explored three components of CRM capabilities, that is, CIMC, CRUC, and CWBC $[31,32,46]$. CIMC refers to "customer identification, customer acquisition, and customer retention," and CRUC refers to "cross-selling and up-selling," while CWBC refers to "reestablishing relationships with lost but profitable customers" [79]. Therefore, this study incorporates the cited three CRM capabilities and proposes that there is a positive influence of CRM capabilities on PSP. The detailed explanation about CIMC, CRUC, and CWBC is discussed below.

2.2.1. Customer Interaction Management Capability. CIMC can be defined as the ability or the skill that the organization uses to identify, attain, and retain profitable customers [31]. In this study context, CIMC refers to the skills and ability of pharmaceutical organization employees that pharmaceutical organizations use to identify, acquire, and retain profitable customers. Many prior studies highlighted the importance of this factor that relates to the effect of CRM capabilities on PSP. For example, Rapp et al. highlighted the importance of CIMC under the umbrella of CRM capabilities, investigated its impact on the sales performance of organizations in the USA, and concluded that CIMC is a significant predictor of the sales performance of organizations [72].

Wang and Feng considered dynamic capabilities as a lens to explore the overall organizational sales performance and confirmed the positive impact of CIMC on the sales growth of an organization [31]. Other studies also revealed the importance of CIMC in increasing sales performance $[46,73]$. In the context of BDA, a prior study only highlighted the importance of CRM in increasing the sales performance of organizations [37] and failed to consider the aforementioned factor in investigating its impact on PSP. Therefore, the current research proposes the influence of CIMC on PSP.

H5: CIMC has a positive impact on PSP.

\subsubsection{Customer Relationship Upgrading Capability.} CRUC refers to the skills and abilities of employees that firms use to increase sales and cross-sales to existing customers with the help of analyzed information [31]. In this study context, CRUC refers to the BDA-related skills and abilities of employees that organizations use to sell large quantities of products or services to existing customers. Previous studies highlighted the importance of this CRM capability on the increment of PSP in different contexts. For example, the study of Wang and Feng in the context of the service sectors of China and the USA explored the importance of CRUC in PSP and developed a scale for this factor [45]. Harrigan et al., in the context of entrepreneurial marketing in small- and medium-sized enterprises, concluded that CRM capabilities, including CRUC, have a positive relationship with the PSP [76]. Other prior studies also described the important role of CRUC in increasing the research performance of organizations [32, 46]. In the context of BDA, Pietro et al. explained CRM as an important factor of marketing and a primary factor in increasing sales performance and suggested its intensive study in the context of BDA [37]. Therefore, the current work proposes that CRUC positively influences the PSP of the pharmaceutical organizations in Pakistan.

H6: CRUC has a positive impact on PSP.

2.2.3. Customer Win-Back Capability. CWBC refers to the skills and ability used by an organization in rebuilding its relationship with lost and inactive profitable customers [31]. CWBC can be defined in this study context as the skills and abilities of employees used by organizations in rebuilding relationships with lost or inactive profitable customers. The important point that must be understood is that CWBC only 
places emphasis on customers who are profitable, that is, those with a positive impact on the PSP.

Customers who harm organizations' performance or sales performance are not acquired by such organizations again. According to the previous literature, CWBC is a significant influencer of PSP; Wang and Feng, for example, concluded that PSP increases with the CWBC of the organization [31]. The study of Alshura considered CWBC and reported its positive impact on the PSP of mobile phone operating organizations [46]. Another study proposed the impact of CRM capabilities on an organization's performance, including CWBC, and reported a high impact [72]. Several other studies also described the importance of CWBC because of its influence on PSP in different contexts $[45,73]$, but they unfortunately lack content that is applicable to BDA. Therefore, the current research proposes that CWBC influences the PSP of pharmaceutical organizations in Pakistan.

H7: CWBC has a positive impact on PSP.

2.2.4. Mediating Role of CRM Capabilities. CIMC is a factor that creates superior CRM capabilities in an organization and is dependent on the quality of the IT system outcomes of such organization [46]. Hence, the CIMC of the organization will increase as the analysis quality of the system improves. CIMC is dependent on how a system takes the daily data of market-related activities. It also relates to how these data are analyzed using AA to provide information on new customers and personalized information on individual customers so as to offer them BCS and retain them in the organization [73]. The study of Wang and Feng considered the mediating role of different CRM capabilities, such as CIMC, between the different benefits of IT systems and PSP and concluded that these capabilities have a significant mediating impact [31]. Therefore, the current study also proposes that CIMC plays a mediating role between the relationships of BDA (BCS, personalization, $\mathrm{AA}$, and IRK) and PSP in pharmaceutical organizations. Therefore, the following hypotheses are formulated.

H5a: CIMC has a mediating impact in the relationship of BCS and PSP.

H5b: CIMC has a mediating impact in the relationship of personalization and PSP.

$\mathrm{H} 5 \mathrm{c}$ : CIMC has a mediating impact in the relationship of AA and PSP.

H5d: CIMC has a mediating impact in the relationship of IRK and PSP.

CRUC is also totally dependent on the quality of analysis that the IT system provides to the employees of organizations [45]. Given the core purpose of CRUC of increasing the quantity of sales and cross-sales to existing profitable customers, the quantity of sales increasing with the IT system provides employees AA information regarding the existing customers to provide those BCS. In this way, the employees of the organization can increase the importance of the product or service in the eyes of existing customers and motivate them to use it regularly. The second factor of cross-sale is possible when the IT system increases employees' relational knowledge by providing personalized information about existing customers so that the employees can provide new customized products or services to existing customers and increase crossselling [31]. Therefore, CRUC is dependent on the quality analysis, service provision information, personalized information, and knowledge that improves the quality of the IT system. The study of Harrigan, in the context of e-CRM, considered the mediating role of CRM capabilities, including CRUC, and concluded that CRUC mediates the impact of IT system benefits on PSP [76]. On the basis of the suggestions provided by previous studies, the current research also proposes that CRUC mediates the relationships among BDA (BCS, personalization, AA, and IRK) and the PSP in pharmaceutical organizations. Thus, the following research hypotheses are formulated.

H6a: CRUC has a mediating impact in the relationship of BCS and PSP.

H6b: CRUC has a mediating impact in the relationship of personalization and PSP.

H6c: CRUC has a mediating impact in the relationship of AA and PSP.

H6d: CRUC has a mediating impact in the relationship of IRK and PSP.

CWBC is also a product of IT systems and is the most important CRM capability [46] because the loss of customers impacts the sales performance severely. CWBC has a double negative impact on organizations because it not only decreases the sales of organizations but also causes the loss of the substantial investment made on acquiring customers. Another reason why CWBC is critical is the ambiguous acquisition of new customers; it rebuilds profitable relationships with the loss of inactive customers [30]. Therefore, to rebuild the relationship with inactive or angry customers, the employees of organizations must obtain their customers' personalized information, provide better services, employ the latest analysis techniques that extract hidden secrets about customers, and improve their customer knowledge. Wang and Feng considered CWBC as a mediator factor among the benefits of IT systems and the PSP and reported that CWBC partially mediates the relationships among IT system and PSP [31]. In this research context, CWBC mediates the relationships between BDA (BCS, personalization, AA, and IRK) and the PSP in pharmaceutical organizations. Therefore, the current research forms the following hypotheses:

H7a: CWBC has a mediating impact in the relationship of BCS and PSP.

H7b: CWBC has a mediating impact in the relationship of personalization and PSP.

H7c: CWBC has a mediating impact in the relationship of AA and PSP.

H7d: CWBC has a mediating impact in the relationship of IRK and PSP. 


\section{Materials and Methods}

3.1. Measures. This research used a structured questionnaire for data collection that was divided into two parts. The first part was about the respondents' demographic information, and the second part contained items of the variables. For content validity, the research adopted measures from prior studies of a similar context. Table 2 presents the items of the questionnaire and the sources of these items. Moreover, a seven-point Likert scale $(1=$ strongly disagree to $7=$ strongly agree) was adopted to numerically measure the items because the seven-point Likert scale is one of the most widely used scales [82-85].

3.2. Pilot Test. Instrument validity is an important issue to be addressed before entering the data collection phase. Pretest and pilot test techniques were adopted to guarantee questionnaire validity. In the pretesting phase, a group of two full professors and three doctoral students with expertise on instrument development were consulted. The questionnaire items were discussed with the experts, and the proper wording, formation, appropriateness, and length of the items were ensured. After pretesting, 40 respondents were chosen from the selected sample size of the research. These respondents were not included in the main research analysis to avoid subsequent behavior. Table 3 presents the results of the pilot testing. The result shows that the loadings of the BCS ranged from 0.936 to 0.948 , with a Cronbach's alpha score of 0.974 . The factor loadings of personalization ranged from 0.817 to 0.875 , with a Cronbach's alpha score of 0.958 . The loading ranges for AA and IRK were 0.813-0.912 and 0.877-0.896, respectively, with Cronbach's alpha scores of 0.940 and 0.987 , respectively. The loading ranges for CIMC, CRUC, and CWBC were $0.803-0.910,0.776-0.943$, and 0.804-0.945, respectively, and the Cronbach's alpha scores were $0.847,0.944$, and 0.950 , respectively. The factor loadings of PSP ranged from 0.919 to 0.935 , with a Cronbach's alpha score of 0.959 . The values of the factor loadings and Cronbach's alpha for all the constructs exceeded the threshold point of 0.7 [86], which ensured the validity of the instrument.

3.3. Sampling and Data Collection. The pharmaceutical organizations of Pakistan were selected as the population for this study, and the survey method was adopted for data collection from the targeted sample to test the research model. The survey method is suitable for analyzing the behavioral relationship among variables [87]. The contact data of the pharmaceutical organizations were obtained from the Drug Regulatory Authority of Pakistan [88], a regulatory body that controls the pharmaceutical organizations of Pakistan. The convenience sampling technique was used to select the sample size as it is suitable for cases in which the availability of respondents varies [89]. First, the human resource departments (HRDs) of the pharmaceutical organizations were contacted and provided with the purpose and brief introduction of the research, as well as an assurance that the data collected from the employees would only be used for research purposes and that the research findings would be shared with them. After securing permission and with the help of the HRDs, data were collected through an online survey from the employees of sales and marketing departments linked with the usage of different sales management systems. An online survey is suitable because of consistent data collection [90]. The G*Power software was used to predict the suitable sample size as it can ensure sample adequacy before and after data collection [91]. The required sample size was 262 at "A priori: Compute the required sample size." Therefore, 750 questionnaires were distributed, and 441 of them were returned with responses. A total of 416 valid responses were selected for final analyses after discarding biased responses. Meanwhile, "Post hoc: Compute achieved power" was applied to the collected sample size of 416 , and the power was determined to be 0.995 , indicating the adequate strength of the study sample.

\section{Results}

The study used SPSS v25 to ensure the validity and reliability of the exploratory factor analysis (EFA). A structural equation modelling (SEM) approach was adopted to test the proposed research model, and AMOS v25 was used to conduct SEM and confirmatory factor analysis (CFA). AMOS is an appropriate tool for CFA and SEM [92] and a powerful tool for estimating specific indirect effects [93]. The demographical information presented through SPSS is shown in Table 4 . The results indicated that the respondents were equally diverse in gender, with $53.6 \%$ males and $46.4 \%$ females. Furthermore, $96.4 \%$ of the respondents had bachelor's or master's degrees, and $94 \%$ of the respondents were aged below 46 years. Therefore, the respondents of the study were young, educated, and equally diverse in gender.

4.1. Measurement Model. The study first confirmed the samples' adequacy using the Kaiser-Meyer-Olkin (KMO) test, and the KMO score was 0.914, which exceeded the cutoff value of 0.8 [94]. After ensuring the samples' adequacy, the central concern of common method bias (CMB) was addressed by adopting Harman's single factor test. The first factor explained the total variance after categorizing all items into eight subgroups below the threshold value of $50 \%$ [95].

The validity and reliability were ensured through Cronbach's alpha, average variance extracted (AVE), and composite reliability (CR). The values of Cronbach's alpha, CR, and AVE ranged from 0.967 to $0.882,0.971$ to 0.883 , and 0.892 to 0.654 , respectively. The values of Cronbach's alpha, $\mathrm{CR}$, and AVE exceeded the threshold values of 0.7, 0.7, and 0.5 , respectively $[82,96]$, thus indicating the absence of reliability and validity issues. Subsequently, EFA was performed to ensure that the measures were according to the respective variables; the results of factor loading ranged from 0.717 to 0.866 and divided the total items into eight factors. The factor loading values exceeded the threshold value of 0.7 , which guaranteed the absence of any factor loading issue 
TABle 2: Questionnaire items.

\begin{tabular}{|c|c|c|}
\hline Variable and sources & & Items \\
\hline \multirow{5}{*}{ Better customer services $[60,61]$} & BCS1 & $\begin{array}{c}\text { "Use of BDA can useful to deal more strategically with internal and/or external } \\
\text { customers." }\end{array}$ \\
\hline & BCS2 & "Use of BDA can help to serve internal and/or external customers." \\
\hline & $\mathrm{BCS} 3$ & "Use of BDA can help to improve the quality of customer service." \\
\hline & BCS4 & "Use of BDA can help to serve customers more creatively." \\
\hline & BCS5 & $\begin{array}{c}\text { "Use of BDA can help to exchange information with internal and/or external } \\
\text { customers." }\end{array}$ \\
\hline \multirow{3}{*}{ Personalization $[62,63]$} & PR1 & "The BDA can help to tailor my services through personalized analytics." \\
\hline & PR2 & $\begin{array}{c}\text { "The BDA can help me to address the personal interests and preferences of customer } \\
\text { by providing more relevant analyzed information." }\end{array}$ \\
\hline & PR3 & $\begin{array}{c}\text { "The BDA can provide me all types of information that customers like to know about } \\
\text { products and services." }\end{array}$ \\
\hline \multirow{3}{*}{ Advanced analytics $[65,66]$} & AA1 & "The analyzed information of BDA can create a competitive advantage." \\
\hline & AA2 & $\begin{array}{c}\text { "The analyzed information of BDA can enable quicker response to change as } \\
\text { compared to a competitor." }\end{array}$ \\
\hline & AA3 & $\begin{array}{c}\text { "The analyzed information of BDA can help to enter new products/services and } \\
\text { markets more quickly than our competitors." }\end{array}$ \\
\hline \multirow{4}{*}{$\begin{array}{l}\text { Improved relation knowledge } \\
{[48,67,68]}\end{array}$} & IRK1 & $\begin{array}{c}\text { "Analyzed information of BDA can be very useful in terms of planning, organizing, } \\
\text { and leading projects." }\end{array}$ \\
\hline & IRK2 & $\begin{array}{c}\text { "Analyzed information of BDA can be very useful in terms of planning and executing } \\
\text { work in a collective environment." }\end{array}$ \\
\hline & IRK3 & "Analyzed information of BDA can be very useful in terms of teaching others". \\
\hline & IRK4 & $\begin{array}{c}\text { "Analyzed information of BDA can be very useful to work closely with customers and } \\
\text { maintain productive user/client relationships." }\end{array}$ \\
\hline \multirow{5}{*}{$\begin{array}{l}\text { Customer interaction management } \\
\text { capability }[31,45,46]\end{array}$} & CIMC1 & "BDA can be helpful to know the current needs and potential needs of the customer." \\
\hline & CIMC2 & "BDA information good enough to create good relationships with key customers." \\
\hline & CIMC3 & $\begin{array}{c}\text { "BDA has the ability to assist regarding maintaining interactive two way } \\
\text { communication with the customers." }\end{array}$ \\
\hline & CIMC4 & $\begin{array}{l}\text { "BDA can help the organizations to dialog with customers on continuous bases and } \\
\text { provide good ways to improve the relationship with a customer." }\end{array}$ \\
\hline & CIMC5 & $\begin{array}{c}\text { "BDA information overall good enough to create and maintain a good relationship } \\
\text { with the customer." }\end{array}$ \\
\hline \multirow{4}{*}{$\begin{array}{l}\text { Customer relationship upgrading } \\
\text { capabilities }[31,45,46]\end{array}$} & & "BDA frequently and systematically measure customer satisfaction." \\
\hline & CRUC2 & "BDA provides formalized techniques for up selling to a key customer." \\
\hline & CRUC3 & "BDA provides formalized techniques for cross-selling to a key customer." \\
\hline & CRUC4 & "BDA extend the share of customers with key customers systematically." \\
\hline \multirow{5}{*}{$\begin{array}{l}\text { Customer win-back capabilities } \\
{[31,45,46]}\end{array}$} & CWBC1 & $\begin{array}{c}\text { "BDA has the assisting ability to compensate any loss and inconvenience with the } \\
\text { customer timely." }\end{array}$ \\
\hline & CWBC2 & $\begin{array}{c}\text { "BDA has the systematic process of interacting with lost or inactive customers for } \\
\text { reestablishing the relationship." }\end{array}$ \\
\hline & CWBC3 & $\begin{array}{c}\text { "BDA has the ability to generate the corrective action alerts immediately with the } \\
\text { customer unhappy with the product and services." }\end{array}$ \\
\hline & & "BDA can help to rebuild a good relationship with migrating or inactive customers." \\
\hline & CWBC4 & $\begin{array}{c}\text { "BDA has the assisting ability to compensate any loss and inconvenience with the } \\
\text { customer timely." }\end{array}$ \\
\hline \multirow{3}{*}{ Perceived sales performance $[80,81]$} & PSP1 & "The utilization of BDA will improve my closing rates." \\
\hline & PSP2 & "Utilization of BDA enables me to analyze reasons for won and lost opportunities." \\
\hline & PSP3 & "The utilization of BDA will improve my overall sales performance." \\
\hline
\end{tabular}

[97]. Table 5 presents the results of factor loadings, Cronbach's alpha, CR, and AVE.

The study elaborated on the square root of AVE to ensure the discriminant validity, as suggested by a prior study [98]. As shown in Table 6, the values of the square root of each construct exceeded those of all interconstructs linked with the variable; hence, no discriminant validity issue existed.

CFA was conducted to verify the consistency and validity of the research model's constructs through AMOS v25. The results of CFA showed that the value of CMIN/DF was 1.365, and the values of CFI, NFI, RFI, IFI, and TLI were 0.989, $0.960,0.953,0.989$, and 0.987 , respectively. The values of RMSEA, PClose, and SRMR were 0.030, 1.000, and 0.061, respectively. According to Hair et al., the threshold point for CMIN/DF is between 1 and 3; SRMR should be less than 0.08; RMSEA should be less than 0.06; PClose should exceed 0.05; and CFI, NFI, RFI, IFI, and TLI should be higher than 0.90 [86]. All the values mentioned above exceeded the cutoff values, thus ensuring the model's good fitness. 
TABLe 3: Pilot testing results.

\begin{tabular}{|c|c|c|c|c|}
\hline Sr. No & Constructs & Items & Loadings & Cronbach's alpha \\
\hline \multirow{5}{*}{1} & \multirow{5}{*}{ Better customer services } & BCS1 & 0.936 & \multirow{5}{*}{0.974} \\
\hline & & BCS2 & 0.939 & \\
\hline & & BCS3 & 0.941 & \\
\hline & & BCS4 & 0.946 & \\
\hline & & BCS5 & 0.948 & \\
\hline \multirow{3}{*}{2} & \multirow{3}{*}{ Personalization } & PR1 & 0.817 & \multirow{3}{*}{0.958} \\
\hline & & PR2 & 0.873 & \\
\hline & & PR3 & 0.875 & \\
\hline \multirow{3}{*}{3} & \multirow{3}{*}{ Advanced analytics } & AA1 & 0.910 & \multirow{3}{*}{0.940} \\
\hline & & AA2 & 0.912 & \\
\hline & & AA3 & 0.813 & \\
\hline \multirow{4}{*}{4} & \multirow{4}{*}{ Improved relational knowledge } & IRK1 & 0.892 & \multirow{4}{*}{0.987} \\
\hline & & IRK2 & 0.877 & \\
\hline & & IRK3 & 0.896 & \\
\hline & & IRK4 & 0.894 & \\
\hline \multirow{5}{*}{5} & \multirow{5}{*}{ Customer interaction management capability } & CIMC1 & 0.803 & \multirow{5}{*}{0.947} \\
\hline & & CIMC2 & 0.864 & \\
\hline & & CIMC3 & 0.910 & \\
\hline & & CIMC4 & 0.814 & \\
\hline & & CIMC5 & 0.787 & \\
\hline \multirow{4}{*}{6} & \multirow{4}{*}{ Customer relationship upgrading capability } & CRUC1 & 0.897 & \multirow{5}{*}{0.944} \\
\hline & & CRUC2 & 0.891 & \\
\hline & & CRUC3 & 0.943 & \\
\hline & & CRUC4 & 0.766 & \\
\hline \multirow{4}{*}{7} & \multirow{4}{*}{ Customer win-back capability } & CWBC1 & 0.932 & \\
\hline & & CWBC2 & 0.946 & \multirow{3}{*}{0.950} \\
\hline & & CWBC3 & 0.804 & \\
\hline & & CWBC4 & 0.918 & \\
\hline \multirow{3}{*}{8} & \multirow{3}{*}{ Perceived sales performance } & PSP1 & 0.935 & \multirow{3}{*}{0.959} \\
\hline & & PSP2 & 0.919 & \\
\hline & & PSP3 & 0.933 & \\
\hline
\end{tabular}

TABLE 4: Demographical information.

\begin{tabular}{lccc}
\hline & Category & Frequency & Percentage \\
\hline \multirow{4}{*}{ Gender } & Male & 223 & 53.6 \\
& Female & 193 & 46.4 \\
& Total & 416 & 100 \\
Education & High school/diploma & 7 & 1.7 \\
& Bachelor & 207 & 49.8 \\
& Master & 194 & 46.6 \\
& Doctor & 8 & 1.9 \\
Age & Total & 416 & 100 \\
& $18-25$ & 57 & 13.7 \\
& $26-35$ & 163 & 39.2 \\
& $36-45$ & 171 & 41.1 \\
& 46 and above & 25 & 6.0 \\
& Total & 416 & 100 \\
\hline
\end{tabular}

4.2. Structure Model. The study subsequently performed path analysis. The value of CMIN/DF was 1.099. The values of CFI, NFI, RFI, IFI, and TLI were 0.999, 0.987, 0.965, 0.999, and 0.997 , respectively. The values of RMSEA, PClose, and SRMR were $0.015,0.960$, and 0.036 , respectively. The values were within the acceptable range and ensured the good fitness of the model [86]. Figure 2 presents the path coefficient and significance level of the proposed research model. According to the results, BCS was positively associated with CIMC $(\beta=0.198, p<0.001)$, CRUC $(\beta=0.095, p<0.050)$,
$\operatorname{CWBC}(\beta=0.282, p<0.001)$, and PSP $(\beta=0.104, p<0.050)$. Personalization was positively associated with CIMC $(\beta=0.125, p<0.050)$, CRUC $(\beta=0.214, p<0.001)$, CWBC $(\beta=0.156, p<0.010)$, and PSP $(\beta=0.129, p<0.050)$. AA was positively associated with CIMC $(\beta=0.189, p<0.001)$, CRUC $(\beta=0.258, p<0.001)$, CWBC $(\beta=0.137, p<0.050)$, and PSP $(\beta=0.117, p<0.050)$. IRK showed significant relationships with CIMC $(\beta=0.292, \quad p<0.001 p<0.001)$, CRUC $(\beta=0.257, p<0.001)$, CWBC $(\beta=0.137, p<0.010)$, and PSP $(\beta=0.106, p<0.050)$. Furthermore, CIMC was positively associated with PSP $(\beta=0.105, p<0.050)$, CRUC had a significant impact on PSP $(\beta=0.106, p<0.050)$, and CWBC had a significant impact on PSP $(\beta=0.198$, $p<0.001)$. Moreover, the adjusted $R$-square $\left(R^{2}\right)$ of CIMC was 0.41 , indicating that the predictor variables caused $41 \%$ of the variance of CIMC. Furthermore, the $R^{2}$ values of CRUC, CWBC, and PSP were 0.45, 0.32, and 0.42, respectively.

4.3. Mediating Analysis Results. To test the mediating roles of CIMC, CRUC, and CWBC among the different relationships of variables, this study used the bootstrapping method on 2000 bootstrap samples at $95 \%$ confidence level to measure the indirect effects. In this study, the specific indirect relations need not be measured due to the complexity of the model and the relations. Therefore, the 
TABLE 5: Results of factor loadings, Cronbach's alpha, composite reliability (CR), and AVE.

\begin{tabular}{|c|c|c|c|c|c|c|}
\hline Sr. no & Constructs & Items & Loadings & Cronbach's alpha & $\mathrm{CR}$ & AVE \\
\hline \multirow{5}{*}{1} & \multirow{5}{*}{ Better customer services } & BCS1 & 0.736 & \multirow{5}{*}{0.921} & \multirow{5}{*}{0.919} & \multirow{5}{*}{0.701} \\
\hline & & BCS2 & 0.764 & & & \\
\hline & & BCS3 & 0.845 & & & \\
\hline & & BCS4 & 0.852 & & & \\
\hline & & BCS5 & 0.849 & & & \\
\hline \multirow{3}{*}{2} & \multirow{3}{*}{ Personalization } & PR1 & 0.801 & \multirow{3}{*}{0.927} & \multirow{4}{*}{0.935} & \multirow{3}{*}{0.829} \\
\hline & & PR2 & 0.779 & & & \\
\hline & & PR3 & 0.825 & & & \\
\hline \multirow{3}{*}{3} & \multirow{3}{*}{ Advanced analytics } & AA1 & 0.807 & \multirow{3}{*}{0.915} & & \multirow{3}{*}{0.785} \\
\hline & & AA2 & 0.754 & & \multirow[t]{2}{*}{0.917} & \\
\hline & & AA3 & 0.733 & & & \\
\hline \multirow{4}{*}{4} & \multirow{4}{*}{ Improved relational knowledge } & IRK1 & 0.830 & \multirow{4}{*}{0.967} & \multirow{4}{*}{0.971} & \multirow{4}{*}{0.892} \\
\hline & & IRK2 & 0.812 & & & \\
\hline & & IRK3 & 0.842 & & & \\
\hline & & IRK4 & 0.866 & & & \\
\hline \multirow{5}{*}{5} & \multirow{5}{*}{ Customer interaction management capability } & CIMC1 & 0.765 & \multirow{5}{*}{0.917} & \multirow{5}{*}{0.913} & \multirow{5}{*}{0.679} \\
\hline & & CIMC2 & 0.776 & & & \\
\hline & & CIMC3 & 0.809 & & & \\
\hline & & CIMC4 & 0.771 & & & \\
\hline & & CIMC5 & 0.761 & & & \\
\hline \multirow{4}{*}{6} & \multirow{4}{*}{ Customer relationship upgrading capability } & CRUC1 & 0.762 & \multirow{5}{*}{0.882} & \multirow{5}{*}{0.883} & \multirow{4}{*}{0.654} \\
\hline & & CRUC2 & 0.735 & & & \\
\hline & & CRUC3 & 0.741 & & & \\
\hline & & CRUC4 & 0.815 & & & \\
\hline & & CWBC1 & 0.717 & & & \\
\hline 7 & Customer win bect combility & CWBC2 & 0.884 & & & \\
\hline 7 & Customer win-back capability & CWBC3 & 0.718 & 0.902 & 0.905 & 0.712 \\
\hline & & CWBC4 & 0.875 & & & \\
\hline & & PSP1 & 0.768 & & & \\
\hline 8 & Perceived sales performance & PSP2 & 0.792 & 0.884 & 0.885 & 0.720 \\
\hline & & PSP3 & 0.804 & & & \\
\hline
\end{tabular}

bootstrapping method that measures specific indirect effects, as suggested by Brown [99], was applied. Table 7 presents the results of the specific indirect effects of the mediating variables. CIMC partiality mediated the impact of BCS on PSP $(\beta=0.120, p<0.050)$, personalization and PSP $(\beta=0.113$, $p<0.050)$, AA and PSP $(\beta=0.119, p<0.050)$, and IRK and PSP $(\beta=0.130, p<0.050)$. CRUC partially mediated the impact of BCS on PSP $(\beta=0.111, p<0.050)$, personalization and PSP $(\beta=0.124, p<0.050)$, AA and PSP $(\beta=0.128$, $p<0.050)$, and IRK and PSP $(\beta=0.129, p<0.050)$. CWBC partially mediated the impact of BCS on PSP $(\beta=0.155$, $p<0.001)$, personalization and PSP $(\beta=0.131, p<0.010)$, AA and PSP $(\beta=0.127, p<0.010)$, and IRK and PSP $(\beta=0.127, p<0.010)$. The results indicated that CRM capabilities (CIMC, CRUC, and CWBC) significantly partially mediated the relationships between BDA measuring variables (BCS, PR, AA, and IRK) and PSP.

\section{Discussion}

In this era of advanced IT, data analyses have become mandatory for the survival of every industry, including pharmaceutical [100-102]. Pharmaceutical organizations in developing countries, especially in Pakistan, are facing grim financial conditions, and BDA is probably one of the possible solutions to address this situation [11, 103, 104]. Keeping in mind the dire need of pharmaceutical organizations, this study proposed a research model that investigates the impact of BDA on PSP and the development of different capabilities in organizations, such as CRM capabilities. With a theoretical foundation, this study considered BDA as resources for enhancing the PSP of pharmaceutical organizations and building CRM capabilities, which also enhance PSP. On the basis of the systematic literature review, this study considered the four most influential and important BDA benefits, namely, BCS, personalization, AA, and IRK, as measuring variables of BDA to test their impact on PSP and proposed that these factors are positive developers of the CRM capabilities (CIMC, CRUC, and CWBC) and PSP of pharmaceutical organizations in Pakistan. The results indicated that BCS was positively associated with CIMC, CRUC, CWBC, and PSP, thus suggesting that the employees of pharmaceutical organizations believe that BDA output information could help them provide BCS, and BCS could develop CIMC, CRUC, and CWBC in pharmaceutical organizations. Moreover, the delivery of BCS will enhance the PSP of pharmaceutical organizations. The results provide an opportunity to conclude the positive 


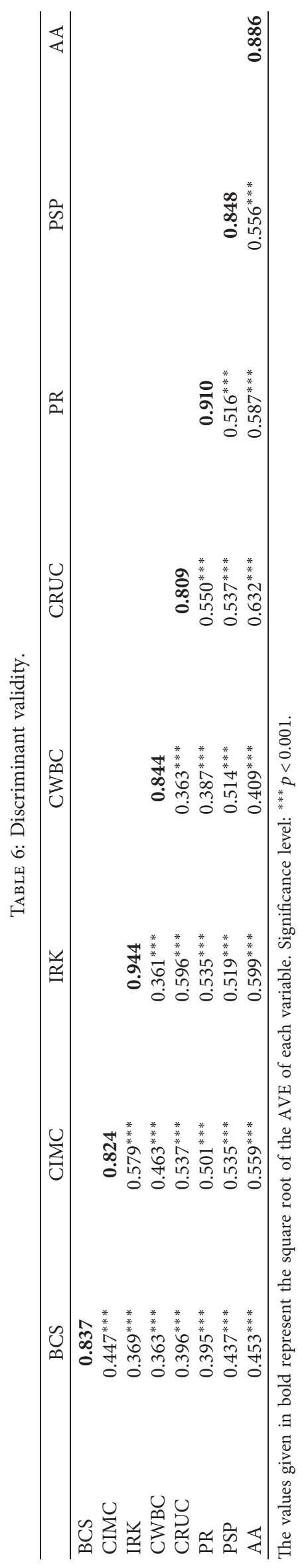




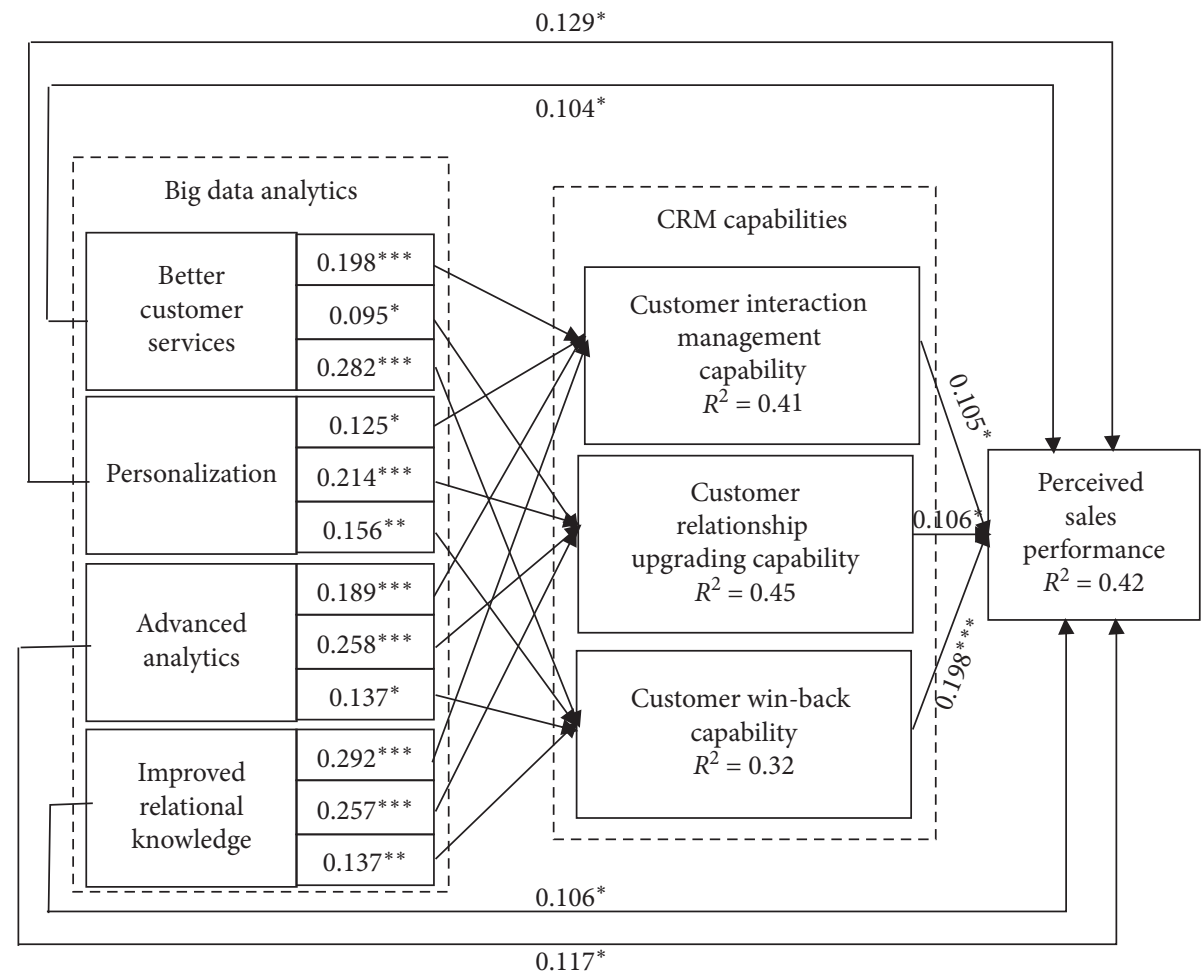

FIgURE 2: SEM results of research model.

TABLE 7: Bootstrapping results to measure the specific indirect effects.

\begin{tabular}{|c|c|c|c|c|c|c|c|}
\hline \multicolumn{4}{|c|}{ Variables } & \multicolumn{4}{|c|}{ Bootstrapping results } \\
\hline $\begin{array}{l}\mathrm{H} . \\
\text { No }\end{array}$ & Independent & Mediator & Dependent & $\begin{array}{l}\text { Lower } \\
\text { bounds }\end{array}$ & $\begin{array}{l}\text { Upper } \\
\text { bounds }\end{array}$ & $\begin{array}{l}\text { Indirect } \\
\text { effects }\end{array}$ & Results \\
\hline $\mathrm{H} 14 \mathrm{a}$ & $\begin{array}{l}\text { Better customer } \\
\text { services }\end{array}$ & $\begin{array}{l}\text { Customer interaction } \\
\text { management capability }\end{array}$ & $\begin{array}{l}\text { Perceived sales } \\
\text { performance }\end{array}$ & 0.001 & 0.045 & $0.120^{*}$ & Supported \\
\hline $\mathrm{H} 15 \mathrm{a}$ & $\begin{array}{l}\text { Better customer } \\
\text { services }\end{array}$ & $\begin{array}{l}\text { Customer relationship } \\
\text { upgrading capability }\end{array}$ & $\begin{array}{l}\text { Perceived sales } \\
\text { performance }\end{array}$ & 0.001 & 0.030 & $0.111^{*}$ & Supported \\
\hline $\mathrm{H} 16 \mathrm{a}$ & $\begin{array}{l}\text { Better customer } \\
\text { services }\end{array}$ & Customer win-back capability & $\begin{array}{l}\text { Perceived sales } \\
\text { performance }\end{array}$ & 0.029 & 0.099 & $0.155^{* * *}$ & Supported \\
\hline $\mathrm{H} 14 \mathrm{~b}$ & Personalization & $\begin{array}{l}\text { Customer interaction } \\
\text { management capability }\end{array}$ & $\begin{array}{l}\text { Perceived sales } \\
\text { performance }\end{array}$ & 0.001 & 0.037 & $0.113^{*}$ & Supported \\
\hline $\mathrm{H} 15 b$ & Personalization & $\begin{array}{c}\text { Customer relationship } \\
\text { upgrading capability }\end{array}$ & $\begin{array}{l}\text { Perceived sales } \\
\text { performance }\end{array}$ & 0.003 & 0.055 & $0.124^{*}$ & Supported \\
\hline $\mathrm{H} 16 \mathrm{~b}$ & Personalization & Customer win-back capability & $\begin{array}{l}\text { Perceived sales } \\
\text { performance }\end{array}$ & 0.013 & 0.058 & $0.131^{* *}$ & Supported \\
\hline $\mathrm{H} 14 \mathrm{c}$ & Advanced analytics & $\begin{array}{l}\text { Customer interaction } \\
\text { management capability }\end{array}$ & $\begin{array}{l}\text { Perceived sales } \\
\text { performance }\end{array}$ & 0.002 & 0.051 & $0.119^{*}$ & Supported \\
\hline $\mathrm{H} 15 \mathrm{c}$ & Advanced analytics & $\begin{array}{c}\text { Customer relationship } \\
\text { upgrading capability }\end{array}$ & $\begin{array}{l}\text { Perceived sales } \\
\text { performance }\end{array}$ & 0.004 & 0.065 & $0.128^{*}$ & Supported \\
\hline $\mathrm{H} 16 \mathrm{c}$ & Advanced analytics & Customer win-back capability & $\begin{array}{l}\text { Perceived sales } \\
\text { performance }\end{array}$ & 0.008 & 0.058 & $0.127^{* *}$ & Supported \\
\hline $\mathrm{H} 14 \mathrm{~d}$ & $\begin{array}{l}\text { Improved relational } \\
\text { knowledge }\end{array}$ & $\begin{array}{l}\text { Customer interaction } \\
\text { management capability }\end{array}$ & $\begin{array}{l}\text { Perceived sales } \\
\text { performance }\end{array}$ & 0.001 & 0.069 & $0.130^{*}$ & Supported \\
\hline $\mathrm{H} 15 \mathrm{~d}$ & $\begin{array}{l}\text { Improved relational } \\
\text { knowledge }\end{array}$ & $\begin{array}{l}\text { Customer relationship } \\
\text { upgrading capability }\end{array}$ & $\begin{array}{l}\text { Perceived sales } \\
\text { performance }\end{array}$ & 0.003 & 0.061 & $0.129^{*}$ & Supported \\
\hline H16d & $\begin{array}{l}\text { Improved relational } \\
\text { knowledge }\end{array}$ & Customer win-back capability & $\begin{array}{l}\text { Perceived sales } \\
\text { performance }\end{array}$ & 0.007 & 0.059 & $0.127^{* *}$ & Supported \\
\hline
\end{tabular}

Significance level ${ }^{*} p<0.050 ;{ }^{* *} p<0.01 ;{ }^{* * *} p<0.001$. 
association of personalization with CIMC, CRUC, CWBC, and PSP. These results suggest that BDA should provide personalized information of customers for the development of CIMC, CRUC, and CWBC in pharmaceutical organizations and enhancement of their PSP.

$\mathrm{AA}$ and IRK were found to be positively associated with CIMC, CRUC, CWBC, and PSP. On the basis of these results, this study suggests that BDA have advanced analytical tools to analyze data and provide AA outcome information to pharmaceutical organizations' employees regarding customers as well as outcome information that increases their relational knowledge. In this way, CIMC, CRUC, and CWBC will be developed in pharmaceutical organizations, and their PSP will increase. The results on the BDA impact on CRM capabilities and PSP are consistent with those of prior studies $[56,58,105]$.

On the basis of the theoretical foundation, this study proposed that CRM capabilities (CIMC, CRUC, and CWBC) are positively associated with the PSP of the pharmaceutical organizations of Pakistan. The SEM results of the research proved that CIMC, CRUC, and CWBC were positively associated with the PSP of pharmaceutical organizations. The results of this study regarding CRM capabilities are consistent with those of previous studies [31, 45, 46]. The results also suggest that the PSP of pharmaceutical organizations increases with their CIMC. Hence, pharmaceutical organizations may sustain their profitable relationships with existing customers with the help of BDA and thereby retain profitable customers. The sustainability of CIMC also increases PSP. Meanwhile, the results indicate that, with the help of BDA, organizations could develop CRUC. That is, organizations can sell more services or products to existing customers or increase profitable customers' frequency of use of products or services. The more products or services are sold or the higher the frequency of use is, the greater the increase in the pharmaceutical organizations' PSP will be. The results also suggest that, with the help of $\mathrm{BDA}$, the pharmaceutical organizations of Pakistan may develop CWBC. Therefore, using $\mathrm{BDA}$, organizations can recover lost or inactive customers in the loop of organizations. Consequently, the PSP of pharmaceutical organizations will increase.

The important mediating roles of CRM capabilities (CIMC, CRUC, and CWBC) between BDA (BCS, personalization, AA, and IRK) and the PSP of pharmaceutical organizations in Pakistan were also considered. The results of the bootstrapping methods proved that CRM capabilities significantly mediated the impact of BDA on PSP. CIMC, CRUC, and CWBC and partially mediated the relationships between BCS and PSP, personalization and PSP, AA and PSP, and IRK and PSP. The results of these mediating effects are consistent with those of prior studies $[31,46,71]$. These results suggest that the BCS, personalization, $\mathrm{AA}$, and IRK measuring variables of $\mathrm{BDA}$ will increase the CIMC, CRUC, and CWBC (CRM capabilities) of organizations. These capabilities will also increase the PSP of pharmaceutical organizations indirectly.

\section{Conclusions}

The prodigious interest of scholars and practitioners in the expected impact of BDA on PSP motivated this research. The literature on $\mathrm{BDA}$ is extensive in terms of benefits, challenges, and adoption but limited in the aspect of its possible impact on PSP enhancement. Therefore, the primary objective of this study was to investigate the impact of BDA on PSP. This research was built on RBV and dynamic capabilities theories. The most prominent BDA benefits were considered to measure the BDA. The impact of BDA on the development of CRM capabilities and PSP and the direct impact of CRM capabilities with PSP were empirically investigated. The mediating role of CRM capabilities between BDA and PSP was also proposed. The empirical findings of this study reveal that BDA benefits, such as BCS, personalization, AA, and IRK, have a substantial impact of CRM capabilities on PSP and indirect impact on PSP through CRM capabilities. Therefore, CRM capabilities, such as CIMC, CRUC, and CWBC, are strong predictors of PSP and play an important mediating role between BDA and PSP. Therefore, this study concluded that BDA could increase PSP and develop CRM capabilities in pharmaceutical organizations and that these capabilities have a direct impact on PSP and mediate the impact of BDA on PSP.

\section{Implications, Limitations, and Future Research}

7.1. Implications. This study contributes to BDA theory and practice in several ways. This research contributes to the theory of BDA impact on PSP in the context of the pharmaceutical organizations of Pakistan, which could be an important lens for technologically enhancing CRM capabilities and PSP particularly in developing countries. Furthermore, this research contributes to the theory of combining RBV and dynamic capabilities theory in the context of BDA's impact on PSP. This study also provides a theoretical basis for researchers who want to intensively investigate the role of BDA in PSP enhancement in the pharmaceutical sector of Pakistan and other developing countries. Moreover, this research offers a novel contribution through CRM capabilities' mediating role in the context of the impact of BDA on PSP that is lacking in the literature. The CRM capabilities discussed in this study have been significantly proved as a booster of organizational sales performance as perceived by the employees. These empirical results enrich the existing role of CRM capabilities in context of measuring the impact of BDA on PSP.

Similarly, this study contributes to BDA practice in several ways. This research bridges the gap between BDA and PSP in the context of the pharmaceutical organizations in Pakistan and provides an opportunity to practice BDA. Pharmaceutical organizations are uncertain after the failure of traditional sales management systems and in search of an alternative. This study solves this problem of pharmaceutical organizations practically in the fact that it provides an alternative for organizations that are dissatisfied with the existing SFA system to improve the sales performance. Therefore, based on this study's results, it has been suggested that the pharmaceutical organizations can efficiently counter the challenges of sales and improve their CRM capabilities by practicing BDA in organizations. Moreover, in order to improve the sales 
performance, the managers are suggested to increase the CRM capabilities and ensure that BDA provides specific information about upgrading and retaining existing customers, creating new customers and winning back lost ones.

7.2. Limitations and Future Research. This research aimed to investigate the impact of BDA on PSP of the pharmaceutical organizations in Pakistan. Despite the noteworthy contributions of this research, a number of limitations remain. On the bases of these limitations, future research directions are suggested. The sample size of this study belongs to a developing country, that is, Pakistan, which might not yield the same results as other developing and developed countries. Future researchers should test the same models in other developing and developed countries to increase the generalizability of the study model. Future research should also conduct longitudinal research to consider the behavioral changes of users. This study considered the four BDA benefits as measuring variables of $\mathrm{BDA}$ to investigate the impact of BDA on PSP and reported the direct positive impact of BDA on PSP and the indirect impact through CRM capabilities. BDA has many other benefits that prior studies have not reported as important benefits of BDA and that this study ignored. Future research can introduce other BDA benefits to extensively investigate the impact of BDA on PSP. This research considered CRM capabilities as a predictor of PSP and a mediator between BDA and PSP. Other important capabilities, such as marketing and dynamic process capabilities, may exist, and their mediating role should also be investigated in this study context. Therefore, future researchers should consider other capabilities as mediators to strengthen the research findings. This study has observed the perceived sales performance based on the personal theory of the respondents and did not focus on the actual sales performance. Therefore, it is our suggestion for future researchers to measure actual sales performance.

\section{Data Availability}

The primary data used to support the findings of this study are available from the corresponding authors upon request (Muhammad Shahbaz; shahbaz755@yahoo.com and Changyuan Gao; gaocy2002@126.com).

\section{Conflicts of Interest}

There are no conflicts of interest among authors.

\section{Acknowledgments}

This study was supported by the NSFC "National Natural Science Foundation of China" under project numbers "71672050" and "71774044".

\section{References}

[1] P. Mikalef, I. O. Pappas, J. Krogstie, and M. Giannakos, “Big data analytics capabilities: a systematic literature review and research agenda," Information Systems and E-Business Management, vol. 16, no. 3, pp. 547-578, 2018.

[2] H. Li, J. Wu, L. Liu, and Q. Li, "Adoption of big data analytics in Healthcare : the efficiency and privacy," in Proceedings of the Pacific Asia Conference on Information Systems, Singapore, July 2015.

[3] T. Nguyen, L. Zhou, V. Spiegler, P. Ieromonachou, and Y. Lin, "Big data analytics in supply chain management: a state-of-the-art literature review," Computers \& Operations Research, vol. 98, pp. 254-264, 2018.

[4] R. H. Hariri, E. M. Fredericks, and K. M. Bowers, "Uncertainty in big data analytics: survey, opportunities, and challenges," Journal of Big Data, vol. 6, no. 1, 2019.

[5] J. Manyika, M. Chui, B. Brown et al., Big Data: The Next Frontier for Innovation, Competition, and Productivity, p. 156, McKinsey Global Institute, New York, NY, USA, 2011.

[6] S. John Walker, "Big data: a revolution that will transform how we live, work, and think," International Journal of Advertising, vol. 33, no. 1, pp. 181-183, 2014.

[7] S. F. Wamba, A. Gunasekaran, S. Akter, S. J.-F. Ren, R. Dubey, and S. J. Childe, "Big data analytics and firm performance: effects of dynamic capabilities," Journal of Business Research, vol. 70, pp. 356-365, 2017.

[8] M. Shahbaz, C. Gao, L. Zhai, F. Shahzad, and Y. Hu, "Investigating the adoption of big data analytics in healthcare: the moderating role of resistance to change," Journal of Big Data, vol. 6, no. 1, pp. 1-20, 2019.

[9] T. Boone, R. Ganeshan, A. Jain, and N. R. Sanders, "Forecasting sales in the supply chain: consumer analytics in the big data era," International Journal of Forecasting, vol. 35, no. 1, pp. 170-180, 2019.

[10] T. H. Davenport, "Analytics 3.0-in the new era, big data will power consumer products and services," Harvard Business Review, vol. 1, pp. 64-72, 2013.

[11] I. Hernandez and Y. Zhang, "Using predictive analytics and big data to optimize pharmaceutical outcomes," American Journal of Health-System Pharmacy, vol. 74, no. 18, pp. 1494-1500, 2017.

[12] P. Raj, A. Raman, D. Nagaraj, and S. Duggirala, "Big data analytics for healthcare," in Computer Communications and Networks, pp. 391-424, Springer, Berlin, Germany, 2015.

[13] A. Eggert and M. Serdaroglu, "Exploring the impact of sales technology on salesperson performance: a taskbase d approach," Journal of Marketing Theory and Practice, vol. 19, no. 2, pp. 169-186, 2011.

[14] E. D. Honeycutt, T. Thelen, S. T. Thelen, and S. K. Hodge, "Impediments to sales force automation," Industrial Marketing Management, vol. 34, no. 4, pp. 313-322, 2005.

[15] R. Jelinek, M. Ahearne, J. Mathieu, and N. Schillewaert, “A longitudinal examination of individual, organizational, and contextual factors on sales technology adoption and job performance," Journal of Marketing Theory and Practice, vol. 14, no. 1, pp. 7-23, 2006.

[16] W. C. Block, J. Golterman, J. Wecksell, and K. Scherburger, "Building blocks for technology-enabled selling," Report R-100-104, Gartner, Stamford, CT, USA, 1996.

[17] C. Speier and V. Venkatesh, "The hidden minefields in the adoption of sales force automation technologies," Journal of Marketing, vol. 66, no. 3, pp. 98-111, 2002.

[18] R. M. Barker, S. F. Gohmann, J. Guan, and D. J. Faulds, "Why is my sales force automation system failing?" Business Horizons, vol. 52, no. 3, pp. 233-241, 2009. 
[19] B. J. Mariadoss, C. Milewicz, S. Lee, and A. Sahaym, "Salesperson competitive intelligence and performance: the role of product knowledge and sales force automation usage," Industrial Marketing Management, vol. 43, no. 1, pp. 136-145, 2014.

[20] D. Nunan, O. Sibai, B. Schivinski, and G. Christodoulides, "Reflections on "social media: influencing customer satisfaction in B2B sales" and a research agenda," Industrial Marketing Management, vol. 75, pp. 31-36, 2018.

[21] R. Agnihotri, R. Dingus, M. Y. Hu, and M. T. Krush, "Social media: influencing customer satisfaction in B2B sales," Industrial Marketing Management, vol. 53, pp. 172-180, 2016.

[22] C. Okoli, "A guide to conducting a standalone systematic literature review," Communications of the Association for Information Systems, vol. 37, no. 1, p. 43, 2015.

[23] J. K. Kiptoo and F. Mugambi Mwirigi, "Factors that influence effective strategic planning process in organizations," IOSR Journal of Business and Management, vol. 16, no. 6, pp. 2319-7668, 2014.

[24] C. Wu, X. Ye, F. Ren, Y. Wan, P. Ning, and Q. Du, "Spatial and social media data analytics of housing prices in Shenzhen, China," PLoS One, vol. 11, no. 10, Article ID e0164553, 2016.

[25] M. Shahbaz, C. Gao, L. Zhai, F. Shahzad, and M. R. Arshad, "Moderating effects of gender and resistance to change on the adoption of big data analytics in healthcare," Complexity, vol. 2020, Article ID 2173765, 13 pages, 2020.

[26] S. Verma and S. Chaurasia, "Understanding the determinants of big data analytics adoption," Information Resources Management Journal, vol. 32, no. 3, pp. 1-26, 2019.

[27] I. D. Dinov, B. Heavner, M. Tang et al., "Predictive big data analytics: a study of parkinson's disease using large, complex, heterogeneous, incongruent, multi-source and incomplete observations," PLoS One, vol. 11, no. 8, Article ID e0157077, 2016.

[28] A. Acharya, S. K. Singh, V. Pereira, and P. Singh, "Big data, knowledge co-creation and decision making in fashion industry," International Journal of Information Management, vol. 42, pp. 90-101, 2018.

[29] M. W. Nyadzayo and S. Khajehzadeh, "The antecedents of customer loyalty: a moderated mediation model of customer relationship management quality and brand image," Journal of Retailing and Consumer Services, vol. 30, pp. 262-270, 2016.

[30] T. Coltman, T. M. Devinney, and D. F. Midgley, "Customer relationship management and firm performance," Journal of Information Technology, vol. 26, no. 3, pp. 205-219, 2011.

[31] Y. Wang and H. Feng, "Customer relationship management capabilities," Management Decision, vol. 50, no. 1, pp. 115129, 2012.

[32] E. R. Simanjuntak, Firmanzah, T. E. Balqiah, and T. Pawitra, "CRM capabilities and marketing effectiveness: the mediating role of interactive marketing implementation," in Proceedings of the Global Marketing Conference, pp. 892-893, Hong Kong, China, July 2016.

[33] T. Coltman, "Can superior CRM capabilities improve performance in banking," Journal of Financial Services Marketing, vol. 12, no. 2, pp. 102-114, 2007.

[34] S. Maklan and S. Knox, "Dynamic capabilities: the missing link in CRM investments," European Journal of Marketing, vol. 43, no. 11-12, pp. 1392-1410, 2009.

[35] M. Ahearne, D. E. Hughes, and N. Schillewaert, "Why sales reps should welcome information technology: measuring the impact of CRM-based IT on sales effectiveness,"
International Journal of Research in Marketing, vol. 24, no. 4, pp. 336-349, 2007.

[36] L. Kung, H. J. Kung, A. Jones-Farmer, and Y. Wang, "Managing big data for firm performance: a configurational approach," in Proceedings of the 2015 Americas Conference on Information Systems AMCIS 2015, pp. 1-9, Fajardo, Puerto Rico, August 2015.

[37] P. Ducange, R. Pecori, and P. Mezzina, "A glimpse on big data analytics in the framework of marketing strategies," Soft Computing, vol. 22, no. 1, pp. 325-342, 2018.

[38] P. Zerbino, D. Aloini, R. Dulmin, and V. Mininno, "Big dataenabled customer relationship management: a holistic approach," Information Processing \& Management, vol. 54, no. 5, pp. 818-846, 2018.

[39] S. K. Singh and A.-N. El-Kassar, "Role of big data analytics in developing sustainable capabilities," Journal of Cleaner Production, vol. 213, pp. 1264-1273, 2019.

[40] Y. Wang and N. Hajli, "Exploring the path to big data analytics success in healthcare," Journal of Business Research, vol. 70, pp. 287-299, 2017.

[41] P. Mikalef, M. Boura, G. Lekakos, and J. Krogstie, "Big data analytics and firm performance: findings from a mixedmethod approach," Journal of Business Research, vol. 98, pp. 261-276, 2019.

[42] J. Karimi, T. M. Somers, and A. Bhattacherjee, "The role of information systems resources in ERP capability building and business process outcomes," Journal of Management Information Systems, vol. 24, no. 2, pp. 221-260, 2007.

[43] Y. Lin and L.-Y. Wu, "Exploring the role of dynamic capabilities in firm performance under the resource-based view framework," Journal of Business Research, vol. 67, no. 3, pp. 407-413, 2014.

[44] M. Wade and J. Hulland, "Review: the resource-based view and information systems research: review, extension, and suggestions for future research," MIS Quarterly, vol. 28, no. 1, pp. 107-142, 2004.

[45] Y. G. Wang and H. Feng, "CRM capability in service industries: conceptualization and scale development," in Proceedings of the 2008 IEEE International Conference on Service Operations and Logistics, and Informatics, pp. 83-88, Beijing, China, October 2008.

[46] M. S. Alshura, "Customer relationship management (CRM) capabilities \& building a sustainable competitive advantage in mobile phone operators in Jordan," International Journal of Business and Management, vol. 13, no. 3, pp. 262-276, 2018.

[47] J. Barney, "Firm resources and sustained competitive advantage," Journal of Management, vol. 17, no. 1, pp. 99-120, 1991.

[48] S. Akter, S. F. Wamba, A. Gunasekaran, R. Dubey, and S. J. Childe, "How to improve firm performance using big data analytics capability and business strategy alignment?" International Journal of Production Economics, vol. 182, pp. 113-131, 2016.

[49] P. Mikalef, J. Krogstie, I. O. Pappas, and P. Pavlou, "Exploring the relationship between big data analytics capability and competitive performance: the mediating roles of dynamic and operational capabilities," Information \& Management, vol. 57, no. 2, 2020.

[50] G. Kim, B. Shin, K. K. Kim, and H. G. Lee, "IT capabilities, process-oriented dynamic capabilities, and firm financial performance," Journal of the Association for Information Systems, vol. 2, pp. 22-33, 2011. 
[51] Y. Wang, L. Kung, W. Y. C. Wang, and C. G. Cegielski, “An integrated big data analytics-enabled transformation model: application to health care," Information \& Management, vol. 55, no. 1, pp. 64-79, 2018.

[52] D. Teece and G. Pisano, "The dynamic capabilities of firms: an introduction," Industrial and Corporate Change, vol. 3, no. 3, pp. 537-556, 1994.

[53] N. F. Doherty and M. Terry, "The role of IS capabilities in delivering sustainable improvements to competitive positioning," The Journal of Strategic Information Systems, vol. 18, no. 2, pp. 100-116, 2009.

[54] N. Saraf, C. S. Langdon, and S. Gosain, "IS application capabilities and relational value in interfirm partnerships," Information Systems Research, vol. 18, no. 3, pp. 320-339, 2007.

[55] N. Wang, H. Liang, W. Zhong, Y. Xue, and J. Xiao, "Resource structuring or capability building? An empirical study of the business value of information technology," Journal of Management Information Systems, vol. 29, no. 2, pp. 325367, 2012.

[56] S. Akter and S. F. Wamba, "Big data analytics in E-commerce: a systematic review and agenda for future research," Electronic Markets, vol. 26, no. 2, pp. 173-194, 2016.

[57] P. Mikalef, M. Boura, G. Lekakos, and J. Krogstie, "Big data analytics capabilities and innovation: the mediating role of dynamic capabilities and moderating effect of the environment," British Journal of Management, vol. 30, no. 2, pp. 272-298, 2019.

[58] C. L. Philip Chen and C.-Y. Zhang, "Data-intensive applications, challenges, techniques and technologies: a survey on big data," Information Sciences, vol. 275, pp. 314-347, 2014.

[59] I. Lee, "Big data: dimensions, evolution, impacts, and challenges," Business Horizons, vol. 60, no. 3, pp. 293-303, 2017.

[60] W. J. Doll and G. Torkzadeh, "Developing a multidimensional measure of system-use in an organizational context," Information \& Management, vol. 33, no. 4, pp. 171-185, 1998.

[61] P. Trivellas and I. Santouridis, "Antecedents of task innovation: the role of management information systems," Procedia-Social and Behavioral Sciences, vol. 73, pp. 683691, 2013.

[62] A. Parasuraman, V. A. Zeithaml, and A. Malhotra, "E-SQUAL," Journal of Service Research, vol. 7, no. 3, pp. 213233, 2005.

[63] H. Xu, H.-H. Teo, B. C. Y. Tan, and R. Agarwal, "The role of push-pull technology in privacy calculus: the case of location-based services," Journal of Management Information Systems, vol. 26, no. 3, pp. 135-174, 2009.

[64] F. Shahzad, G. Xiu, I. Khan, and J. Wang, "m-government security response system: predicting citizens' adoption behavior," International Journal of Human-Computer Interaction, vol. 35, no. 10, pp. 899-915, 2019.

[65] S. Ji-fan Ren, S. Fosso Wamba, S. Akter, R. Dubey, and S. J. Childe, "Modelling quality dynamics, business value and firm performance in a big data analytics environment," International Journal of Production Research, vol. 55, no. 17, pp. 5011-5026, 2017.

[66] E. Raguseo and C. Vitari, "Investments in big data analytics and firm performance: an empirical investigation of direct and mediating effects," International Journal of Production Research, vol. 56, no. 15, pp. 5206-5221, 2018.

[67] J. J. Jiang, G. Klein, C. V. Slyke, and P. Cheney, "A note on interpersonal and communication skills for IS professionals: evidence of positive influence," Decision Sciences, vol. 34, no. 4, pp. 799-812, 2003.

[68] G. Kim, B. Shin, and O. Kwon, "Investigating the value of sociomaterialism in conceptualizing it capability of a firm," Journal of Management Information Systems, vol. 29, no. 3, pp. 327-362, 2012.

[69] R. Glavee-Geo, A. A. Shaikh, and H. Karjaluoto, "Mobile banking services adoption in Pakistan: are there gender differences?" International Journal of Bank Marketing, vol. 35, no. 7, pp. 1088-1112, 2017.

[70] M. Z. I. Lallmahomed, N. Lallmahomed, and G. M. Lallmahomed, "Factors influencing the adoption of E-government services in Mauritius," Telematics and Informatics, vol. 34, no. 4, pp. 57-72, 2017.

[71] A. Negahban, D. J. Kim, and C. Kim, "Unleashing the power of mCRM: investigating antecedents of mobile CRM values from managers' viewpoint," International Journal of HumanComputer Interaction, vol. 32, no. 10, pp. 747-764, 2016.

[72] A. Rapp, K. J. Trainor, and R. Agnihotri, "Performance implications of customer-linking capabilities: examining the complementary role of customer orientation and CRM technology," Journal of Business Research, vol. 63, no. 11, pp. 1229-1236, 2010

[73] E. Plakoyiannaki and N. Tzokas, "Customer relationship management: a capabilities portfolio perspective," Journal of Database Marketing \& Customer Strategy Management, vol. 9, no. 3, pp. 228-237, 2002.

[74] C. Lehrer, A. Wieneke, J. vom Brocke, R. Jung, and S. Seidel, "How big data analytics enables service innovation: materiality, affordance, and the individualization of service," Journal of Management Information Systems, vol. 35, no. 2, pp. 424-460, 2018.

[75] D. Arunachalam, N. Kumar, and J. P. Kawalek, "Understanding big data analytics capabilities in supply chain management: unravelling the issues, challenges and implications for practice," Transportation Research Part E: Logistics and Transportation Review, vol. 114, pp. 416-436, 2018.

[76] P. Harrigan, E. Ramsey, and P. Ibbotson, "Entrepreneurial marketing in SMEs: the key capabilities of e-CRM," Journal of Research in Marketing and Entrepreneurship, vol. 14, no. 1, pp. 40-64, 2012.

[77] P. Mikalef and J. Krogstie, "Examining the interplay between big data analytics and contextual factors in driving process innovation capabilities," European Journal of Information Systems, pp. 1-28, 2020.

[78] G. Li, W. Li, Z. Jin, and Z. Wang, "Influence of environmental concern and knowledge on households' willingness to purchase energy-efficient appliances: a case study in shanxi, China," Sustainability, vol. 11, no. 4, p. 1073, 2019.

[79] W. Reinartz, M. Krafft, and W. D. Hoyer, "The customer relationship management process: its measurement and impact on performance," Journal of Marketing Research, vol. 41, no. 3, pp. 293-305, 2004.

[80] D. N. Behrman and W. D. Perreault, "Measuring the performance of industrial salespersons," Journal of Business Research, vol. 10, no. 3, pp. 355-370, 1982.

[81] G. K. Hunter and W. D. Perreault, "Sales technology orientation, information effectiveness, and sales performance," Journal of Personal Selling \& Sales Management, vol. 26, no. 2, pp. 95-113, 2006.

[82] K. Finstad, "Response interpolation and scale sensitivity: evidence against 5-point scales," The Journal of Usability Studies, vol. 5, pp. 104-110, 2010. 
[83] C. C. Preston and A. M. Colman, "Optimal number of response categories in rating scales: reliability, validity, discriminating power, and respondent preferences," Acta Psychologica, vol. 104, no. 1, pp. 1-15, 2000.

[84] J. A. Krosnick and S. Presser, "Question and questionnaire design," in Handbook of Survey Research, Stanford University, Stanford, CA, USA, 2010.

[85] S. Presser, M. P. Couper, J. T. Lessler et al., "Methods for testing and evaluating survey questions," Public Opinion Quarterly, vol. 68, no. 1, pp. 109-130, 2004.

[86] J. F. Hair, W. C. Black, B. J. Babin, and R. E. Anderson, Multivariate Data Analysis, Pearson Prentice Hall, Upper Saddle River, NJ, USA, 2010.

[87] P. R. Newsted, S. L. Huff, and M. C. Munro, "Survey instruments in information systems," MIS Quarterly, vol. 22, no. 4 , p. $553,1998$.

[88] DRAP, List of Valid Drug Manufacturing Units Operating in Pakistan, Drug Regulatory Authority of Pakistan, Islamabad, Pakistan, 2019, https://www.dra.gov.pk/docs/15112019_ final_list_of_units.pdf.

[89] M. Saunders, P. Lewis, and A. Thornhill, Research Methods for Business Students, Prentice Hall, Upper Saddle River, NJ, USA, 2016.

[90] A Defranc, S Van Den Broucke, R Leroy et al., "Measuring oral health behaviour in Flemish health care workers: an application of the theory of planned behaviour," Community Dental Health, vol. 25, no. 2, pp. 107-114, 2008.

[91] F. Faul, E. Erdfelder, A.-G. Lang, and A. Buchner, "G* power 3: a flexible statistical power analysis program for the social, behavioral, and biomedical sciences," Behavior Research Methods, vol. 39, no. 2, pp. 175-191, 2007.

[92] B. M. Byrne, Structural Equation Modeling with AMOS: Basics Concepts, Applications, and Programming, Routledge, Abingdon, UK, 2016.

[93] T. V. der Heidt and D. Scott, "Rethinking the role of external collaboration in product innovation," International Journal of Entrepreneurship and Innovation Management, vol. 15, no. 1-2, pp. 59-90, 2012.

[94] M. S. Bartlett, "A note on the multiplying factors for various $\chi 2$ approximations," Journal of the Royal Statistical Society: Series B (Methodological), vol. 16, no. 2, pp. 296-298, 1954.

[95] P. M. Podsakoff, S. B. MacKenzie, and N. P. Podsakoff, "Sources of method bias in social science research and recommendations on how to control it," Annual Review of Psychology, vol. 63, no. 1, pp. 539-569, 2012.

[96] M. Sarstedt, C. M. Ringle, D. Smith, R. Reams, and J. F. Hair, "Partial least squares structural equation modeling (PLSSEM): a useful tool for family business researchers," Journal of Family Business Strategy, vol. 5, no. 1, pp. 105-115, 2014.

[97] B. Dutta, M.-H. Peng, and S.-L. Sun, "Modeling the adoption of personal health record (PHR) among individual: the effect of health-care technology self-efficacy and gender concern," Libyan Journal of Medicine, vol. 13, no. 1, 2018.

[98] C. Fornell and D. F. Larcker, "Evaluating structural equation models with unobservable variables and measurement error," Journal of Marketing Research, vol. 18, no. 1, pp. 39-50, 1981.

[99] R. L. Brown, "Assessing specific mediational effects in complex theoretical models," Structural Equation Modeling: A Multidisciplinary Journal, vol. 4, no. 2, pp. 142-156, 1997.

[100] F. A. Batarseh and E. A. Latif, "Assessing the quality of service using big data analytics: with application to healthcare," Big Data Research, vol. 4, pp. 13-24, 2016.
[101] J. Wu, H. Li, L. Liu, and H. Zheng, "Adoption of big data and analytics in mobile healthcare market: an economic perspective," Electronic Commerce Research and Applications, vol. 22, pp. 24-41, 2017.

[102] M. U. Sarwar, M. K. Hanif, R. Talib, A. Mobeen, and M. Aslam, "A survey of big data analytics in healthcare," International Journal of Advanced Computer Science and Applications, vol. 8, pp. 355-359, 2017.

[103] Meyer-Massetti and Conen, "Continuous quality improvement for healthcare process improvement," Ther Umschau Revue Thérapeutique, vol. 69, pp. 347-352, 2007.

[104] Z. U. Nisa, A. Zafar, and F. Sher, "Assessment of knowledge, attitude and practice of adverse drug reaction reporting among healthcare professionals in secondary and tertiary hospitals in the capital of Pakistan," Saudi Pharmaceutical Journal, vol. 26, no. 4, pp. 453-461, 2018.

[105] S. A. Hossain, "Big data analytics in education: prospects and challenges," in Proceedings of the 2015 4th International Conference on Reliability, Infocom Technologies and Optimization (ICRITO) (Trends and Future Directions), vol. 1, pp. 1-10, Noida, India, September 2015. 